\title{
Large Depolarization Induces Long Openings of Voltage-Dependent Calcium Channels in Adrenal Chromaffin Cells
}

\author{
Toshinori Hoshi and Stephen J Smith \\ Department of Physiology and Section of Molecular Neurobiology, Yale University School of Medicine, New Haven, \\ Connecticut 06510
}

\begin{abstract}
Single $\mathrm{Ca}^{2+}$-channel currents in bovine adrenal chromaffin cells were studied with the patch-clamp technique using $\mathrm{Ba}^{2+}$ as the charge carrier. Depolarizing pulses to voltages less than $+10 \mathrm{mV}$ from holding voltage of $-60 \mathrm{mV}$ elicited short openings with a mean life time of less than 1 msec. Depolarization to more positive voltages elicited longer openings with a mean life time of about $3 \mathrm{msec}$ in addition to the short openings similar to those observed at less positive voltages. Following large depolarizing prepulses, 2 types of "tail" openings, one with a mean duration of less than $1 \mathrm{msec}$ and the other with a mean duration of $4 \mathrm{msec}$, were observed. In the presence of a dihydropyridine BAY K 8644 , openings with a mean duration of more than 12 msec were present. Depolarization-induced long openings and BAY $K$ 8644-produced long openings differed in the first latency and open-time properties. The results could be explained in terms of multiple open states of one type of $\mathrm{Ca}^{2+}$ channel. A kinetic model with at least 2 open states is required to explain activation of $\mathrm{Ca}^{2+}$ channels in chromaffin cells.
\end{abstract}

Voltage-dependent $\mathrm{Ca}^{2+}$ channels in excitable membranes open briefly in response to depolarizations and mediate influx of $\mathrm{Ca}^{2+}$ ions, which subsequently regulate a variety of cellular processes, including exocytosis in neurons and endocrine cells. Properties of voltage-dependent $\mathrm{Ca}^{2+}$ channels thus affect those of subsequent $\mathrm{Ca}^{2+}$-dependent processes. The amount of $\mathrm{Ca}^{2+}$ influx is influenced by how long the $\mathrm{Ca}^{2+}$ channels stay open. In addition, microscopic spatial distribution of the cytoplasmic free $\mathrm{Ca}^{2+}$ transient corresponding to a given total amount of $\mathrm{Ca}^{2+}$ will be strongly influenced by the temporal pattern of individual channel openings (see Chad and Eckert, 1984; Fogelson and Zucker, 1985; Simon and Llinás, 1985). Therefore, information concerning gating properties of $\mathrm{Ca}^{2+}$ channels is important in undcrstanding kinetics of $\mathrm{Ca}^{2+}$-dependent cellular processes, such as neurotransmitter release from nerve terminals. $\mathrm{Ca}^{2+}$ channels in nerve terminals, however, have been relatively inaccessible to electrophysiological studies. $\mathrm{Ca}^{2+}$ channels in endocrine cells, which share many properties with nerve terminals, have been used as a model for presynaptic $\mathrm{Ca}^{2+}$-channels.

Early studies of the single $\mathrm{Ca}^{2+}$-channel currents in various

\footnotetext{
Received Apr. 7, 1986; revised Aug. 7, 1986; accepted Aug. 8, 1986.

This work was supported in part by National Institute of Health Grant NS16671 and RR-05358 to S. J S.

Correspondence should be addressed to Toshinori Hoshi, Department of Neurobiology, Stanford University School of Medicine, Stanford, CA 94305.

Copyright (C) 1987 Society for Neuroscience $0270-6474 / 87 / 020571-10 \$ 02.00 / 0$
}

preparations suggested that the $\mathrm{Ca}^{2+}$ channel had only $\mathrm{I}$ open state with a mean life time of approximately $1 \mathrm{msec}$ and that the channel activation kinetics could be explained by a sequential 3-state model (Brown et al., 1982; Fenwick et al., 1982b; Cavalie et al., 1983 ). This model was proposed in part because the open time histogram was fitted reasonably well by a singleexponential component and the closed time histogram by a sum of 2 exponential components. However, recent single-channel studies indicate that the 3-state model is inadequate to explain the activation process. Some of the evidence against the 3-state model include the following: (1) First latency or waiting time to the first opening of the snail $\mathrm{Ca}^{2+}$ channels is slower than predicted by the 3-state model (Brown et al., 1984b, c). (2) Voltage dependence of the time constants of the 2 closed time components is inconsistent with the 3-state model (Hagiwara and Ohmori, 1983). (3) Studies of single $\mathrm{Ca}^{2+}$ channels in heart cells and neurons found that some dihydropyridine drugs, such as Ca-agonist BAY K 8644, promote a long-lived open state (Hess et al., 1984; Kokubun and Reuter, 1984; Nowycky et al., $1985 \mathrm{a}, \mathrm{b})$. Long openings similar to those observed in the presence of BAY K 8644 were also observed even without the drug at a very low frequency (Hess et al., 1984; Nowycky et al., $1985 \mathrm{~b}$ ). This second open state in the absence of the drug is inconsistent with the 3-state model. It is not known presently what causes the appearance of the long openings without the drug.

In the present paper, kinetic properties of single $\mathrm{Ca}^{2+}$ channels in adrenal chromaffin cells were studied using the patch-clamp technique. Voltage dependence of $\mathrm{Ca}^{2+}$ channel openings was examined in detail. Two types of $\mathrm{Ca}^{2+}$ channel openings with different mean durations, one type with less than $1 \mathrm{msec}$ and the other with 3-6 msec, were found. Long openings were made more probable by depolarization. In addition, openings with a mean duration of more than $12 \mathrm{msec}$ were observed in the presence of BAY K 8644. All 3 types of openings were similar in the unitary current amplitude. The results indicate that the 3-state model is inadequate to explain the gating and that a model with at least 2 open and 3 or 4 closed states is necessary. The long-lived open state favored by depolarization could underlie activity-dependent enhancement of secretion observed in some synapses.

\section{Materials and Methods}

Cell culture. Bovine adrenal chromaffin cells from calves were prepared and maintained in culture as described previously (Hoshi et al., 1984) except that the cells were often plated on coverslips that were not coated with collagen. The cells were maintained up to $14 \mathrm{~d}$ in culture.

Patch clamp. Cell-attached configuration of the patch-clamp tech- 
a
$+10 \mathrm{~m}$

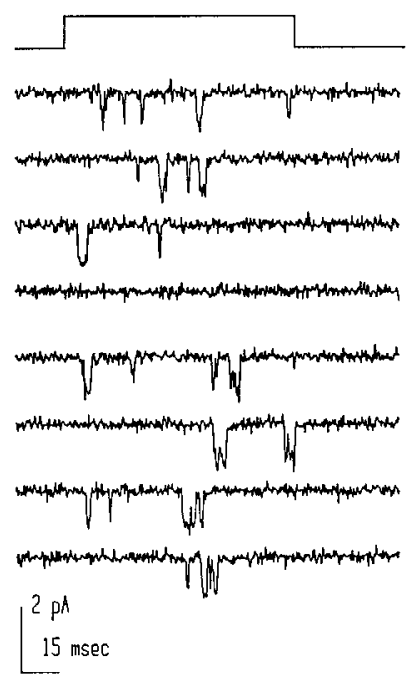

b

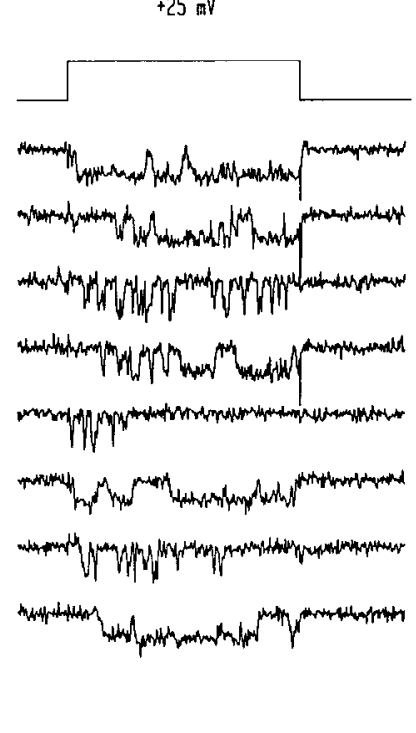

Figure 1. Single $\mathrm{Ca}^{2+}$ channel openings in response to $90 \mathrm{msec}$ depolarizing pulses from the holding voltage of $-60 \mathrm{mV} . a$, Openings at $+10 \mathrm{mV}$. $b$, Openings at $+25 \mathrm{mV}$. Data were filtered at $1 \mathrm{kHz}$ and digitized at $0.3 \mathrm{msec} /$ point. This patch contained 2 channels. The traces are not from consecutive records. The same patch as in Figures 3-5.

nique of Hamill et al. (1981) was used to record $\mathrm{Ca}^{2+}$ channel currents using $\mathrm{Ba}^{2+}$ as the charge carrier. Electrodes were pulled from borosilicate glass (Atlantic Biomedical, Waltham, MA) and coated with Sylgard (Dow Corning, Midland, MI). A fire-polished electrode was sealed onto a relatively spherical cell and then the entire cell was often lifted off the coverslip by raising the electrode to avoid formation of a long cytoplasmic bridge between the cell and the patch caused by drifting of the hydraulic micromanipulator. Data were collected from the patches with seal resistances greater than $20 \mathrm{G} \Omega$. Typical seal resistances were 80-100 $\mathrm{G} \Omega$. The pipettes were filled with $96 \mathrm{mM} \mathrm{BaCl}_{2}, 10 \mathrm{~mm}$ HEPES, pH 7.2 (with $\mathrm{BaOH}$ ). Two types of bath solutions were used: (1) $140 \mathrm{mM} \mathrm{NaCl}$, $2.8 \mathrm{mM} \mathrm{KCl}^{2} \mathrm{mM} \mathrm{MgCl}_{2}, 1 \mathrm{mM} \mathrm{CaCl}_{2}, 10$ HEPES (pH 7.2 with $\mathrm{NaOH}$ ); and (2) $142.8 \mathrm{~mm} \mathrm{~K}$ aspartate, $5 \mathrm{mM} \mathrm{MnCl}_{2}, 2 \mathrm{MgCl}_{2}, 10 \mathrm{HEPES}$ (pH 7.2 with $\mathrm{KOH}$ ). The former solution will be referred to as "normal" saline solution and the latter as "high $\mathrm{K}$ " solution. Unless otherwise noted, data presented were obtained using high-K solution. High-K solution decreased the cell input resistance and maintained the cell potential around $0 \mathrm{mV}$. Cultured chromaffin cells in normal saline solution often have very high input resistances, and openings of a few ion channels are sometimes enough to trigger action potentials (Fenwick et al., 1982a). High-K solution effectively avoided this problem. Even large $\mathrm{Ca}^{2+}$-dependent $\mathrm{K}^{+}$channels could be recorded in the cell-attached configuration without any distortions using high- $K$ solution (unpublished observations). The cells were typically bathed in high-K solution for 10-20 min before the recording began. All the voltages referred to are relative to the cell resting potential. With normal saline solution, the cell resting potential was around -60 to $-70 \mathrm{mV}$ and with high-K solution it was around $0 \mathrm{mV}$. The holding potential relative to the cell resting potential was -10 to $-20 \mathrm{mV}$ when normal saline solution was used and -70 to $-60 \mathrm{mV}$ when high-K solution was used. Depolarizing pulses were delivered every 4 or $5 \mathrm{sec}$. All experiments were done at room temperature $\left(25^{\circ} \mathrm{C}\right)$.

Data acquisition and analysis. Experiments were performed using a PDP 11/23-based minicomputer, and data were analyzed using a PDP 11/73-based minicomputer. The output of the clamp amplifier was analug-filtered through an 8-pole Bessel filter and digitized at the frequencies indicated in the legends. Data were stored on magnetic disks for analyses. Leakage and capacitative currents were corrected in 2 steps. Linear leak and capacitative currents were first subtracted by scaling the average current response to 25 small depolarizing pulses, which did not open any channels, from each trace. When possible, any residual transient currents were subtracted using the average of the traces with no detectable channel openings as the template. In some cases, digitized data were further digitally filtered using a Gaussian digital filter routine as presented in Colquhoun and Sigworth (1983).

Opening and closing transitions were detected using $50 \%$ of the unitary current amplitude obscrved at a particular voltage as the criterion. Open and closed events that lasted up to the end of a pulse were excluded from the duration analyses. When 2 events overlapped, the open event durations were randomly assigned. When more than 2 events overlapped, they were discarded. The number of channels in a patch was determined by observing the maximum number of channels open simultaneously. Often during the course of an experiment some channels dropped out. The channel activity disappeared with time even though the seal resistance remained unchanged. This was most frequently observed when the cells were not lifted off from the coverslip. Because some channels dropped out, overlapping events appeared to occur clustered together in time from one depolarization epoch to another. A patch with only one observable channel was very rarely obtained. $\mathrm{Ca}^{2+}$ channels appeared to exist in clusters on the cell surface. Even when similar-sized clcetrodes were used, some patches contained a large number of channels and others contained none. In many cases overlapping events were very infrequently observed even in the patches that contained more than 1 channel since the probability of the channel being open was small at the voltages examined.

Open and closed time histograms are presented so that the numbers of events whose durations are equal to or greater than the times indicated on the abscissa are plotted. First latency histograms are presented so that the numbers of sweeps with the waiting times to the first opening (or the probabilities of the waiting time) that are less than the times indicated on the abscissa are plotted. When the first latency histograms were displayed in the probability units, the histograms were corrected for the number of active channels in the patch by taking $n$th root of the tail distributions of the first latency histograms. Cumulative histograms were chosen because of their inherent smoothing property. Duration histograms were fitted with a sum of exponential curves first by eye and then by the gradient search nonlinear least-square method (Bevington, 1969). No weighing factor was used in the fit. The number of exponential components to use for fitting was determined visually from the semilogarithmic plots of the histograms. In the cases where the number of events obtained was large, density histograms were also constructed and fitted using the same procedure. The time constants obtained using the density histograms were similar to those obtained using the cumulative histograms.

\section{Results}

\section{Single-channel openings}

Figure 1 shows the single $\mathrm{Ca}^{2+}$ channel activity recorded at +10 $\mathrm{mV}$ (a) and at $+25 \mathrm{mV}$ (b) in response to 90 msec pulses from $-60 \mathrm{mV}$. At $+10 \mathrm{mV}$, all of the openings were quite short in duration and a large portion of the openings were not well resolved. At $+25 \mathrm{mV}$, apparently 2 types of openings with similar unitary current amplitudes but with different durations were found. Some of the openings were as short as those found at $+10 \mathrm{mV}$. Others were much longer in duration. These 2 types of openings were observed within a single depolarizing pulse. The first opening during a pulse was not always a "short" or "long" opening. In most of the patches, no noticeable clustering of long openings across different traces was observed, although in others clustering was apparent.

\section{Ensemble averages and $1-V$ curve}

Ensemble averages of the channel activity recorded at different voltages are shown in Figure $2 a$. These traces were taken from a patch containing several channels to facilitate collection of the cell-attached "macroscopic" currents. In general, the time courses of the averaged traces were similar to those of the whole-cell $\mathrm{Ca}^{2+}$-channel currents recorded using isotonic $\mathrm{Ba}^{2+}$ as the charge carrier (unpublished observations; also see Figure 10 in Fenwick et al., 1982b). A peak current-voltage ( $I-V)$ curve constructed from these cell-altached "macroscopic" currents is shown in Figure $2 b$. The maximum current amplitude was observed at 
a

-10, 10. $20,40 \mathrm{mV}$
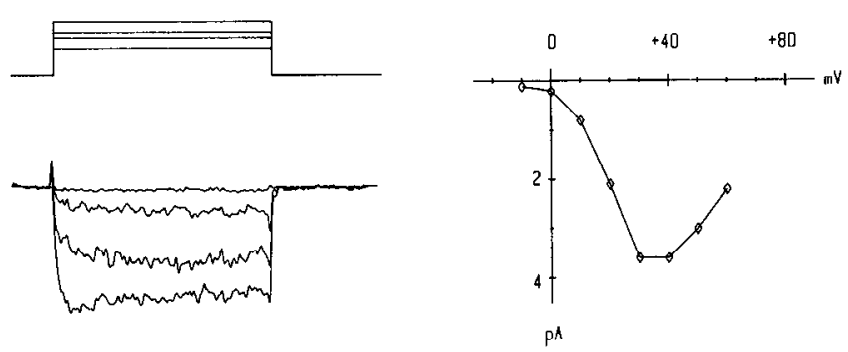

$1.6 \mathrm{ph}$

$10 \mathrm{msec}$

Figure 2. Ensemble averages and $I-V$ curve. $a$, Ensemble averages of the traces elicited in response to $60 \mathrm{msec}$ depolarizing pulses from -60 $\mathrm{mV}$ to the voltages indicated (current traces, from top to bottom, -10 , +10 , +20 , and $+40 \mathrm{mV}$ ). Between 10 to 90 traces were averaged at each voltage. Data were filtered at $1 \mathrm{kHz}$ and digitized at $0.2 \mathrm{msec} /$ point. The averaged traces were digitally filtered with a cut-off frequency of $650 \mathrm{~Hz}$. The patch contained more than 5 channels. $b$, Peak $I-V$ curve constructed from the averaged traces shown in $a$.

+30 to $+40 \mathrm{mV}$. This indicated that the probability of the channel being open reached the peak value at voltages more positive than $+40 \mathrm{mV}$. The observed maximum current voltage was 15-20 mV more positive than that obtained from the wholecell data reported in Fenwick et al. (1982b), assuming that the ccll resting potential was around $0 \mathrm{mV}$ in this study. Although the traces did not contain any obvious net outward channels, it is possible that the observed "macroscopic" currents also included openings of outward channels. Thus, it is not clear whether the apparent inactivation of the ensemble average currents observed at voltages more positive than +30 to $+40 \mathrm{mV}$ reflects genuine inactivation of $\mathrm{Ca}^{2+}$ channels.

\section{Open time histograms}

The open time histogram constructed from the traces recorded at $+10 \mathrm{mV}$ is shown in Figure 3 (histogram a). The histogram was fairly well fitted by a single-exponential component with a time constant of $0.87 \mathrm{msec}$, although there were often more long events than predicted from the single-exponentially distributed dwell time.

The open time histogram constructed from the traces recorded at $+25 \mathrm{mV}$ is also shown in Figure 3 (histogram b). As expected from the presence of 2 types of openings, the histogram was fitted not by a single-exponential component but by a sum of 2 exponential components as indicated by the presence of 2 linear components in the semilogarithmic plot. Time constants of the 2 components at this voltage were 1.0 and $4.1 \mathrm{msec}$.

Voltage dependence of the time constants of the 2 open time components is shown in Figure $4 a$. The time constant of the short component was only slightly voltage dependent and was in the range of 0.4-1 msec. The time constant of the long component also appeared to be slightly voltage dependent in the voltage range examined, increasing slightly with depolarization in the figure shown. At voltages more positive than $+25 \mathrm{mV}$, the time constant of the long component saturated at 3-5 msec, or 3-5 times greater than that of the short component in most of the patches. In other patches, the time constant of the long

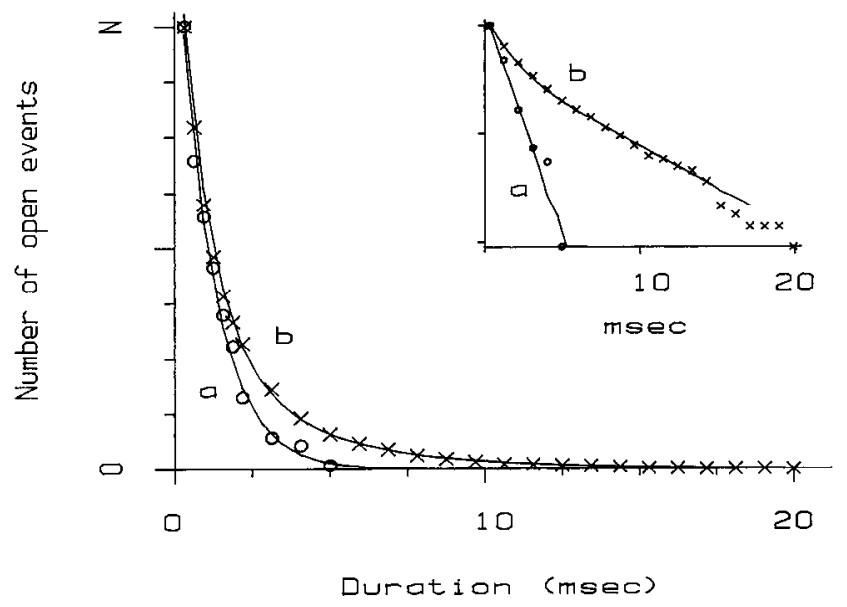

Figure 3. Open time histograms at +10 and $+25 \mathrm{mV}$. Histogram shows the open time distribution at $+10 \mathrm{mV}(a)$ and at $+25 \mathrm{mV}(b)$. Inset, Same histograms in semilogarithmic scale. The histogram at +10 $\mathrm{mV}$ was fitted with a single exponential with a time constant of 0.87 msec. The histogram at $+25 \mathrm{mV}$ was fitted with a sum of 2 exponentials with time constants of 1.0 and $4.1 \mathrm{msec}$. The number of events used $(N)$ for the histogram at $+10 \mathrm{mV}$ was 112 and for the histogram at +25 $\mathrm{mV}$ was 1614. The same patch as in Figures 1, 4, and 5.

component was less voltage dependent than that shown in Figure $4 a$.

Relative amplitudes of the 2 open time components were voltage dependent (Fig. $4 b$ ). Relative amplitudes of the components were measured by the weighing factors of the 2 exponential components used to fit the cumulative histograms. Thus, the amplitudes represented the fractions of the total charge movement through the channels attributed to each component. The frequency of the long openings increased progressively with depolarization, and their relative amplitudes saturated around 0.3 at $+25 \mathrm{mV}$ in this patch. In others, the frequency did not appear to saturate with depolarization up to +25 to $+30 \mathrm{mV}$. At low voltages (less than 0 to $+5 \mathrm{mV}$ ), long-duration openings were observed in some patches, but the frequencies were too low for recognition of a separate component in the duration histogram.

Relative amplitudes of the short and long open time components varied among the patches examined. In some of the patches, the open time histograms could be fitted reasonably well by a single exponential at voltages as positive as +20 to $+25 \mathrm{mV}$. In others, description of the open time histogram at 0 or $+10 \mathrm{mV}$ required a sum of 2 exponentials. One of the variables that appeared to influence the amplitudes of the short and long components was the bath solution. In many of the experiments where the bath solution was normal saline solution, open time histograms were well described by a single exponential even at relatively positive voltages, provided that the apparent resting potential was sufficiently negative $(-60$ to -70 $\mathrm{mV}$ ). When high-K solution was used to stabilize the cell resting potential, the relative amplitude of the long component was often greater compared with the results obtained using normal saline solution. The unitary current amplitudes of well-resolved short and long openings were similar at the voltages examined $(0$ to $+35 \mathrm{mV})$. The average amplitudes of the short openings, however, were smaller than those of the long openings because a larger portion of the short openings were too brief to be well resolved. 

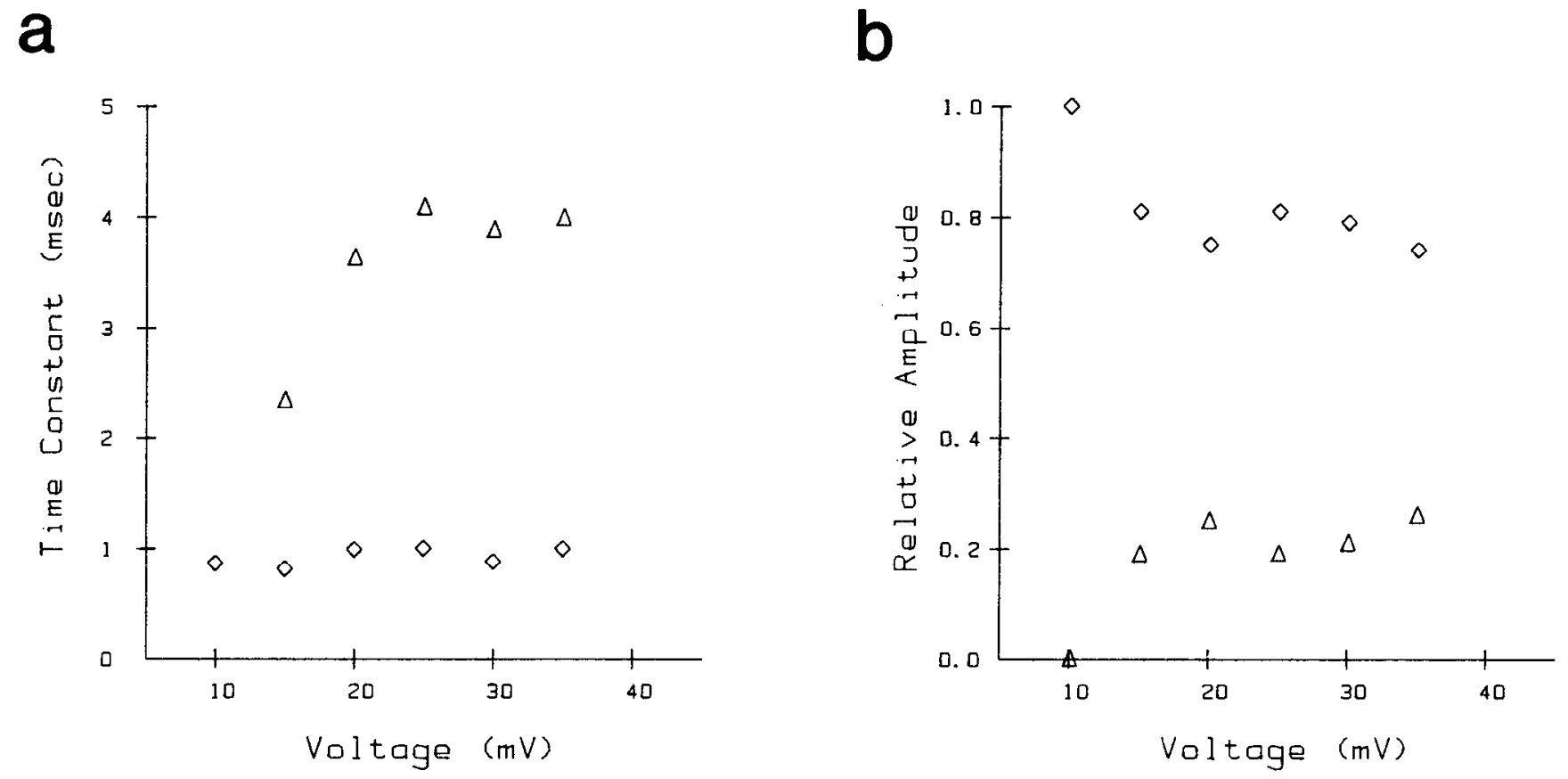

Figure 4. Voltage dependence of time constants (a) and relative amplitudes $(b)$ of the 2 open time components. At $+10 \mathrm{mV}$, the histogram was fitted fairly well by a single exponential. At other voltages, the histograms were fitted with a sum of 2 exponentials. In $b$, relative amplitudes of the short component are represented by diamonds and those of the long component by triangles. Relative amplitudes were determined from the weighing factors of the 2 exponential components to fit the cumulative open time histograms. Data are from the same patch as shown in Figures 1,3 , and 5 .

\section{First-latency histograms \\ Voltage dependence}

First-latency histograms were constructed to describe the waiting time to the first channel opening (Fig. 5). The histograms describe the probability that a channel has opened by the time indicated on the abscissa since the onset of the pulse. The histograms were not fitted by a single-exponential function. Simple average first latency became progressively shorter with depolarization. The final plateau level reached at each voltage was not necessarily unity, although the level varied considerably among the patches examined. In some patches, the final plateau level was unity if the pulse duration was sufficiently long and the voltage sufficiently positive. In others, however, several traces with no openings were observed even at very positive voltages, resulting in a nonunity plateau level in the first-latency histogram. These blank traces were often observed clustered together in time as reported earlier in heart cells (Hess et al., 1984).

\section{First latencies of short and long openings}

The first-latency histograms of the channels whose open time histograms were described by a sum of 2 exponentials were further analyzed by separating the traces into 2 groups depending on the duration of the first opening event during each depolarizing pulse. When the duration of a first opening was shorter than an operationally determined criterion duration, the trace was included in the "short" group; otherwise, the trace was included in the "long" group. The criterion duration was usually 3-4 times greater than the time constant of the short component in the open time histogram. Thus, the first-latency histogram of the "long" group primarily reflected the behavior of the openings that belonged to the long component of the open time histogram, and the histogram of the "short" group reflected that of the openings in the short component of the open time histogram. Figure 6 compares the first latencies of the "short" and "long" groups at $+25 \mathrm{mV}$. The open time histogram of this particular patch was fitted by a sum of 2 exponential components with time constants of 0.6 and 3 msec. Relative amplitudes were 0.72 and 0.28 , respectively. The criterion duration was $1.9 \mathrm{msec}$. Thus, approximately $83 \%$ of the events included in the "long" group belonged to the long exponential component of the open time histogram and the other $17 \%$ in the shortest of the 2 components. Similarly, $84 \%$ of the events in the "short" group belonged to the short open time component and the other $16 \%$ to the long component. Simple average first latencies during 60 msec pulses at this voltage for the "short" and "long" groups were 6.6 and $7.4 \mathrm{msec}$, respectively. The first latency for the "long" group was consistently slower than that for the "short" group at voltages less than +25 or $+30 \mathrm{mV}$. The "long" events opened following a greater delay than the "short" events. The differences between the 2 histograms shown in Figure 6 were significant at 0.1 but not 0.05 level using Kolmogorov-Smirnov 2 -sample hypothesis testing. At more positive voltages, the differences between the 2 groups were less consistent. Since the imperfect grouping of the traces into the 2 groups would undercstimate any differences in the first latencies of the 2 groups, true differences are expected to be greater than observed. This analysis is also affected by missed events and by false events. Effects of missed events and false events have not been quantitatively assessed.

\section{Depolarizing prepulses: tail currents}

If the $\mathrm{Ca}^{2}$ channel had only 1 open state, open durations at 1 voltage should be independent of how the channel reached that 


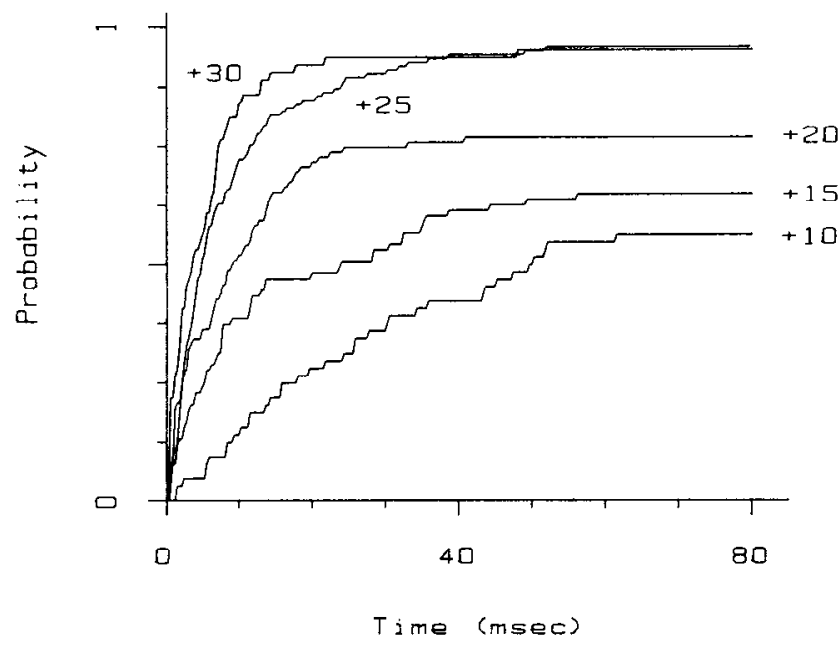

Figure 5. First latency histograms of $\mathrm{Ca}^{2+}$ channel openings. The histograms show the probability that a channel has opened by the time since the onset of the pulse (abscissa). Data were filtered at $1 \mathrm{kHz}$ and sampled at $0.3 \mathrm{msec} /$ point. Holding voltage was $-60 \mathrm{mV}$. The patch contained 2 observable channels. Same patch as in Figures 1, 3, and 4.

voltage. For example, openings at $0 \mathrm{mV}$ should be identical whether the channel reached $0 \mathrm{mV}$ from $-70 \mathrm{mV}$ or from +80 $\mathrm{mV}$. When the patch was depolarized from the holding voltage of $-70 \mathrm{mV}$ to $0 \mathrm{mV}$, brief openings were observed (Fig. 7a), as described earlier in this paper. The open time histogram could be fitted by a single exponential with a time constant of 0.23 msec (Fig. 8, histogram a). This particular patch contained only 1 observable channel. The time course of the ensemble average of the traces (bottom trace in Fig. 7a) was not clearly observed above the hackground noise level because the probability of the channel being open was very small at this voltage.

Single $\mathrm{Ca}^{2+}$ channel openings were also recorded at $0 \mathrm{mV}$ following $500 \mathrm{msec}$ depolarizing prepulses to $+80 \mathrm{mV}$ (Fig. $7 \mathrm{~b}$ ). Following the prepulses, 2 types of openings with different durations were observed. Some of the openings were as brief as the openings observed without the prepulses. However, others were much longer. Note that these long openings were most often observed immediately after stepping down to $0 \mathrm{mV}$ from $+80 \mathrm{mV}$. Thus, they represented "tail" openings of the $\mathrm{Ca}^{2+}$ channel. The open time histogram was no longer fitted by a single exponential but required a sum of at least 2 exponentials (Fig. 8, histogram b). In the data shown in Figure 8, time constants were 0.6 and $4 \mathrm{msec}$. The fraction of the openings belonging to the long component was 0.3 . The short component of the open time histogram is probably identical to the component observed without the prepulse, although the time constant values were somewhat different. The long tail openings were also observed at other voltages ( 0 to $+25 \mathrm{mV}$ ) following depolarizing pulses to $+80 \mathrm{mV}$. At very negative voltages (e.g., $-70 \mathrm{mV}$ ), almost all the tail openings were extremely short in duration and difficult to measure. No obvious clustering of the traces with long openings was observed.

The bottom trace in Figure $7 b$ is an ensemble average of the traces with the prepulses ("macroscopic" tail current). The time course of the tail current was described by a sum of at least 2 exponentials. The short openings were primarily responsible for the rapidly decaying part of the tail current and the long openings were responsible for the slowly decaying component. Wholecell tail currents in chromaffin cells have been shown to have

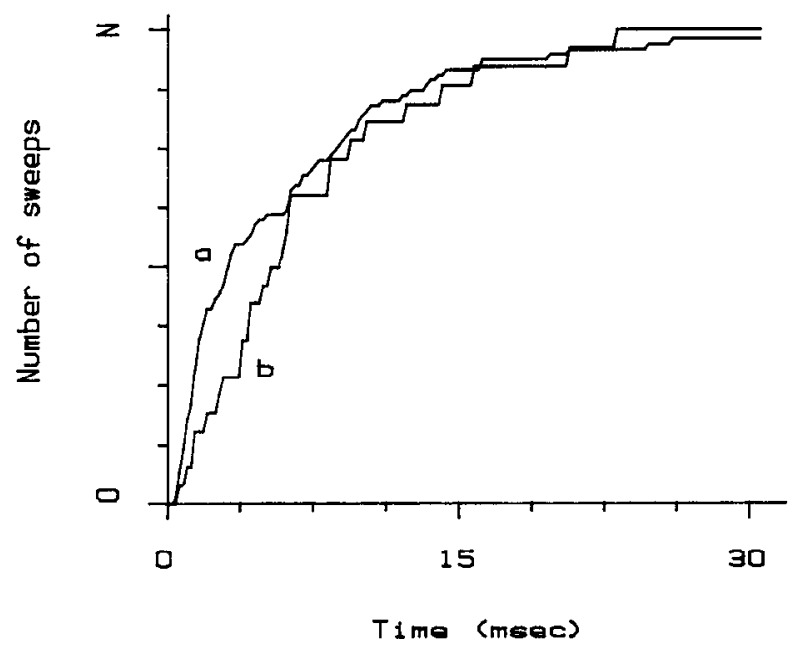

Figure 6. Comparison of the first latencies of the "short" $(a)$ and "long" $(b)$ openings. Pulses to $+25 \mathrm{mV}$ from $-60 \mathrm{mV}$ were applied for $60 \mathrm{msec}$, and the data were filtered at $1 \mathrm{kHz}$ and sampled at $0.2 \mathrm{msec} /$ point. The sweeps were separated into 2 groups depending on the duration of the first open event. The criterion duration was $1.9 \mathrm{msec}$. First latencies of open events $<1.9 \mathrm{msec}$ are represented by histogram $a$ and of those $\geq 1.9 \mathrm{msec}$ by histogram $b . N$ was $95(a)$ and $26(b)$. Traces without any openings were included in neither group. This patch contained 2 observable channels, and the open time histogram of the channels were described by 2 exponential components with time constants of 0.6 and 2.9 msec. Relative amplitudes of the 2 components were 0.72 and 0.28 , respectively. a

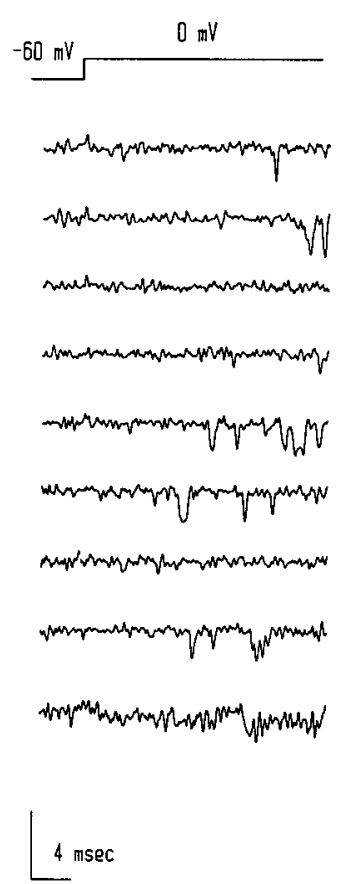

6

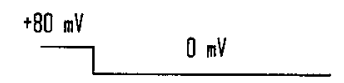

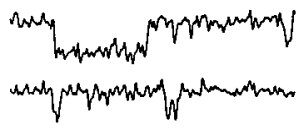

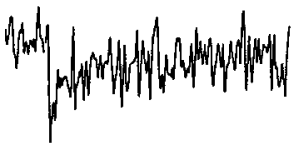

Figure 7. Effects of depolarizing prepulses on the $\mathrm{Ca}^{2+}$ channel openings. $a, \mathrm{Ca}^{2+}$ channel openings elicited in response to pulses from -60 to $0 \mathrm{mV} . b, \mathrm{Ca}^{2+}$ channel openings at $0 \mathrm{mV}$ following $400 \mathrm{msec}$ prepulses to $+80 \mathrm{mV}$. Bottom traces in $a$ and $b$ are the ensemble averages. The scale bar represents $2 \mathrm{pA}$ for the individual traces and $0.5 \mathrm{pA}$ for the average currents. Data were filtered at $1.5 \mathrm{kHz}$ and sampled at 0.08 $\mathrm{msec}$ /point. The same patch as in Figures 8-10. The traces are not from consecutive records. 


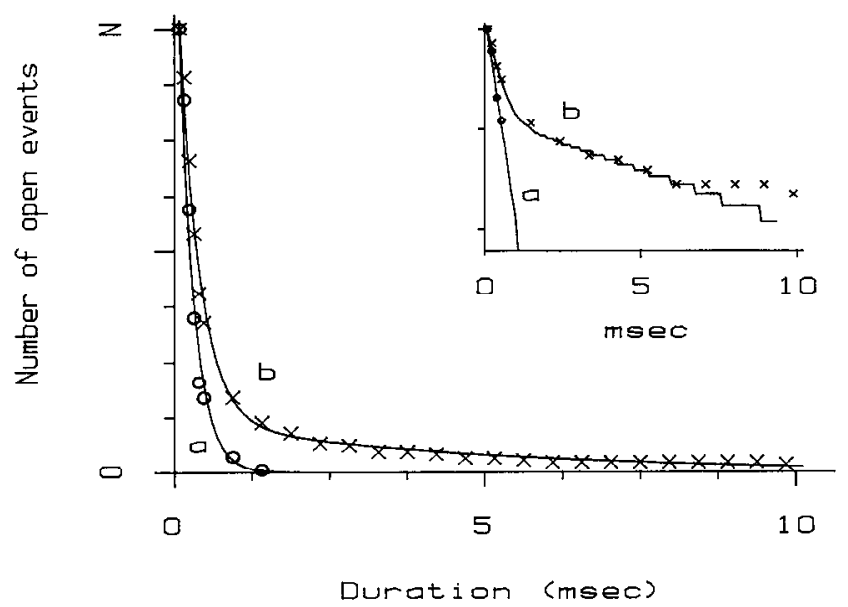

Figure 8. Effects of depolarizing prepulses on the $\mathrm{Ca}^{2+}$ channel open time histogram. Open time histograms constructed from the events without the prepulses $(a)$ and those following depolarizing prepulses $(b)$. Histogram $a$ was fitted with a single exponential component with a time constant of $0.23 \mathrm{msec}$, and histogram $b$ with a sum of 2 exponential components with time constants of 0.6 and $4.0 \mathrm{msec}$. The number of events $(N)$ used for the histograms of the openings without the prepulses and of the events with the prepulses was 169 and 221 , respectively. The same patch as in Figures 7, 9, and 10.

more than 1 exponential component (Fenwick et al., 1982b; Hoshi et al., 1984). The ensemble average particularly resembles the whole-cell tail current observed at voltages around $0 \mathrm{mV}$ following a large depolarizing prepulse (unpublished observations). That the openings were observed following long depolarizing prepulses indicated that at least some of the $\mathrm{Ca}^{2+}$ channels in chromaffin cells do not undergo an appreciable amount of inactivation at very positive voltages.

Since many of the short openings observed were not well resolved, the average amplitudes of the short openings were

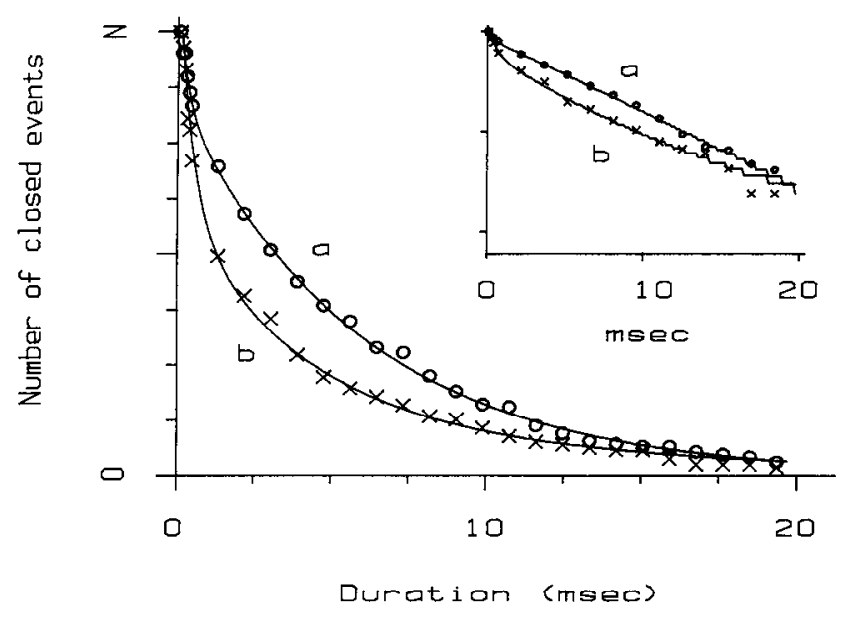

Figure 9. Effects of depolarizing prepulses on the closed time histogram of the $\mathrm{Ca}^{2+}$ channcl. The closed timc histogram (a) for the control events (no depolarizing prepulses) was fitted with a sum of 2 exponentials with time constants of 0.60 and $3.7 \mathrm{msec}$ and that for the events following depolarizing prepulse $(b)$ with a sum of 3 exponentials with time constants of $0.29,3.1$, and $11.4 \mathrm{msec}$. The number of events $(N)$ used for the histograms of the events without the prepulses and with the prepulses was 169 and 187, respectively. Inset, Same histograms in semilogarithmic scale. The same patch as in Figures 7, 8, and 10.

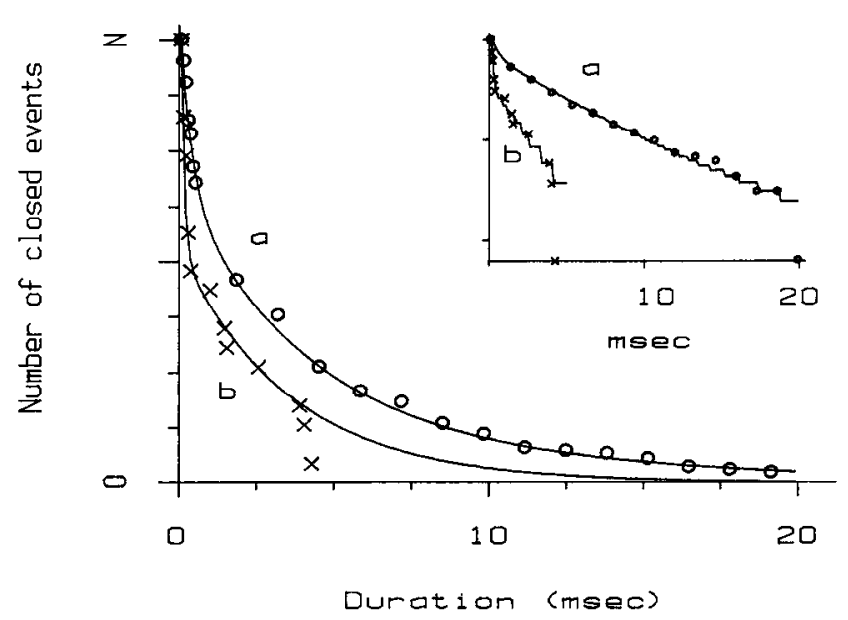

Figure 10. Comparison of the closed time histograms of the events following the "short" $(a)$ and "long" $(b)$ openings. Closed events were divided into 2 groups depending on the duration of the immediately preceding open events (see text). The criterion duration was $1.4 \mathrm{msec}$. The closed time histogram of the "short" group represents the histogram of the events that immediately followed the openings whose durations were shorter than the criterion duration. The histogram of the events following the short openings was fitted with a sum of 3 exponentials with time constants of $0.4,4.0$, and $10 \mathrm{msec}$. Their relative amplitudes were $0.43,0.44$, and 0.13 , respectively. The histogram of the events following the long openings was fitted by a sum of 2 exponentials with time constants of 0.11 and $3.4 \mathrm{msec}$. Their relative amplitudes were 0.8 and 0.2 , respectively. The number of events $(N)$ for the "short" group histogram and for the "long" group histogram was 164 and 23, respectively.

smaller than those of the long openings. However, amplitudes of the reasonably well resolved short openings were similar to those of the long openings.

The closed time histograms from traces with and without the depolarizing prepulses are compared in Figure 9. Note that this particular patch contained only 1 observable channel. Although the histograms were constructed from the nonstationary events, they could be used to compare effects of the prepulses. The closed time histogram of events without depolarizing prepulses was fitted by a sum of 2 exponentials. Time constants of the 2 components were 0.60 and $3.7 \mathrm{msec}$ and their relative amplitudes were 0.25 and 0.71 , respectively. The closed time histogram of the events with the depolarizing prepulses was best fitted by a sum of 3 exponentials. Time constants were $0.29,3.1$, and $11.4 \mathrm{msec}$. The relative amplitudes were $0.41,0.43$, and 0.16 . Three components of the closed time histograms were consistently observed when the long openings were present.

The closed time histogram of the events with the prepulses was analyzed further in the following way. Closed events were separated into "short" and "long" groups depending on the durations of the immediately preceding open events. If a closed event followed an opening whose duration was smaller than a critcrion duration, the closed cvent belonged to the "short" group; otherwise, the event belonged to the "long" group. The grouping criterion was $1.4 \mathrm{msec}$. The duration histogram of the closed events immediately following open events longer than $1.4 \mathrm{msec}$ and that of the events following openings shorter than $1.4 \mathrm{msec}$ are shown in Figure 10. The "short" group histogram was described by a sum of 3 exponentials with time constants of $0.40,4.0$, and $10 \mathrm{msec}$. Time constants of the 3 components were similar to those in the duration histogram of all the closed 
a

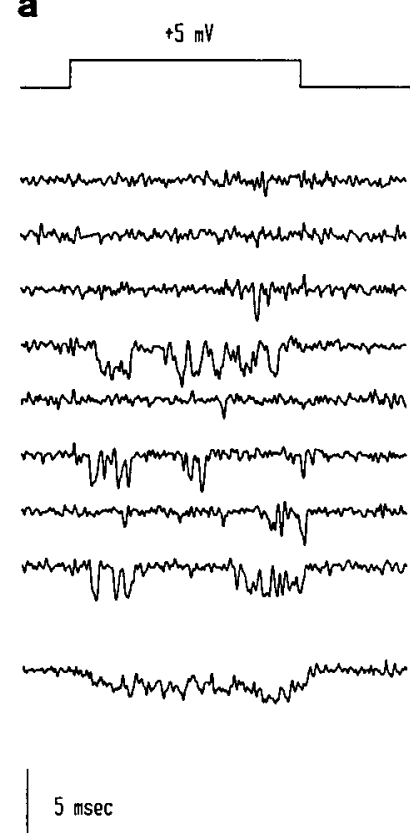

b
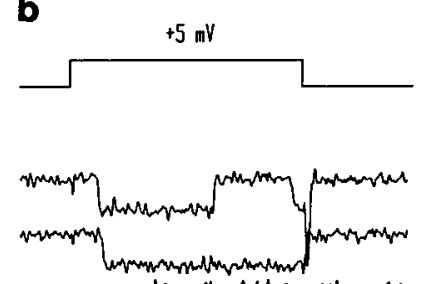

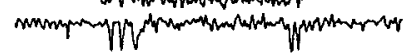

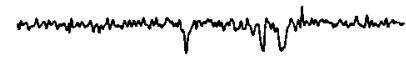

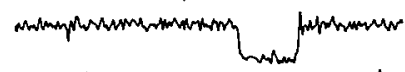

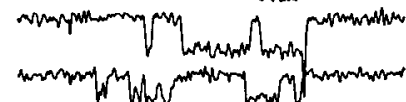

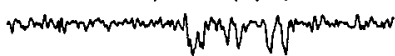

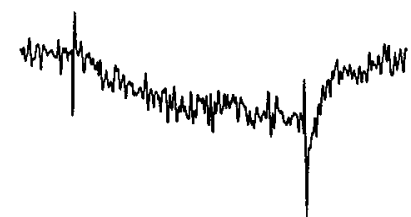

Figure 11. Effects of BAY K 8644 on the $\mathrm{Ca}^{2+}$ channel openings. a, $\mathrm{Ca}^{2+}$ channel openings recorded at $+5 \mathrm{mV}$ before application of $\mathrm{BAY}$ $\mathrm{K}$ 8644. $b, \mathrm{Ca}^{2+}$ channel openings recorded at $+5 \mathrm{mV}$ in the presence of $5 \mu \mathrm{M}$ BAY K 8644. BAY K 8644, $50 \mu \mathrm{M}$, was added to the bath so that the final bath concentration was $5 \mu \mathrm{M}$. Bottom traces are ensemble averages of the traces in each group. The scale bar represents $2 \mathrm{pA}$ for the individual traces and $0.5 \mathrm{pA}$ for the average currents. Data were filtered at $1 \mathrm{kHz}$ and sampled at $0.1 \mathrm{msec} /$ point. The same patch as in Figures 12 and 13. The traces are not from consecutive records.

events. The "long" group histogram was fitted by a sum of 2 exponentials with time constants of 0.11 and $3.4 \mathrm{msec}$. The shortest component in the "long" group probably reflects the brief closures observed within the long open events. Since the relative amplitude of this component was small compared with those of other components, this did not show up as a separated component when the histogram of all the closed events was made (see Fig. 9), but it was probably responsible for the observation that the time constant of the shortest component of the histogram of the events following the depolarizing prepulses was smaller than that of the histogram of the events without the prepulses.

Dependence of the long tail openings on the prepulse voltage has not been examined systematically. In some patches depolarizing prepulses to $+40 \mathrm{mV}$ were effective in inducing long tail openings at $0 \mathrm{mV}$. In 1 patch, the duration of the prepulses to $+80 \mathrm{mV}$ was varied ( $1 \mathrm{sec}$ or $500 \mathrm{msec}$ ). Time constants of the 2 open time components at $0 \mathrm{mV}$ were not affected by the difference in the prepulse duration.

Relative frequencies of the short and long tail openings following depolarizing prepulses varicd among the patches cxamined. In some patches, almost all of the openings were "short." Although effects of the depolarizing prepulses on the open time histograms were reversible most of the time, in 1 patch, application of the depolarizing prepulses resulted in irreversible increase in the open time. Fits of the open time histograms at 0 $\mathrm{mV}$ required a sum of 2 exponentials even without depolarizing prepulses. This effect could not be reversed by application of hyperpolarizing prepulses.

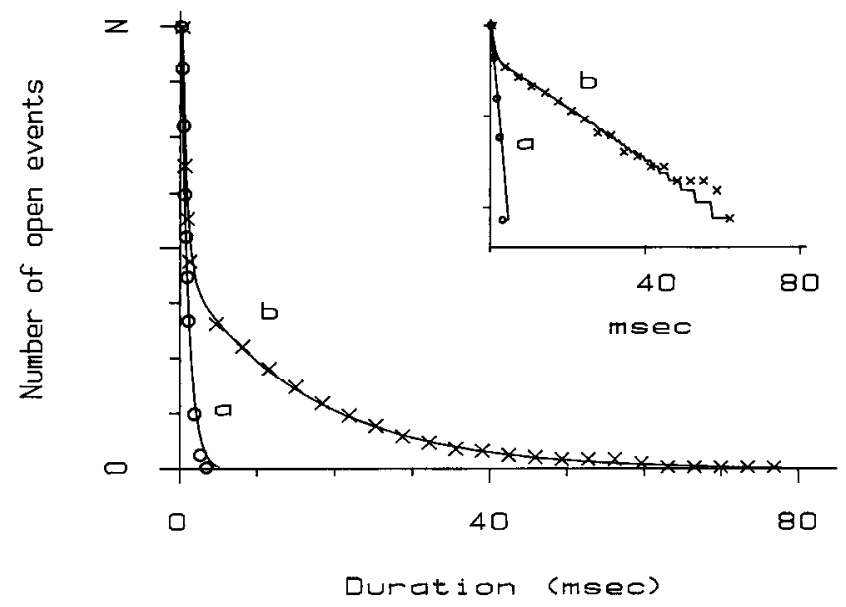

Figure 12. Comparison of normal and BAY K 8644-treated channel open time histograms. Open time histograms of the control $(a)$ and BAY $\mathrm{K}$ 8644-treated $\mathrm{Ca}^{2+}$ channels $(b)$. The control histogram was fitted with a single exponential component with a time constant of $0.6 \mathrm{msec}$ and the histogram of BAY K 8644-treated channels was fitted with a sum of 2 exponential components with time constants of 1.0 and $18 \mathrm{msec}$. The number of the events $(N)$ used for the control histogram and for the histogram of the events with BAY K 8644 was 282 and 302, respectively. The same patch as in Figures 11 and 13.

\section{Effects of different holding voltages}

Hyperpolarizing prepulses to $-120 \mathrm{mV}$ or weak depolarizing prepulses to $-50 \mathrm{mV}$ from the holding voltage of $-70 \mathrm{mV}$, which did not elicit any openings, did not noticeably affect open time, closed time, or first latency histograms. Voltage depcndence or kinetics of activation of the whole-cell $\mathrm{Ca}^{2+}$-channel currents is also largely independent of the holding voltage (unpublished observation).

\section{Effects of BAY K 8644}

Certain dihydropyridines, such as BAY K 8644, have been shown to enhance the $\mathrm{Ca}^{2+}$-channel currents by promoting long openings in other preparations (Hess et al., 1984; Kokubun and Reuter, 1984; Nowycky et al., 1985a, b). Effects of BAY K 8644 on the $\mathrm{Ca}^{2+}$ channels in chromaffin cells were studied to see if depolarization-induced long openings reported in this study were identical to BAY K 8644-produced long openings. Effects of BAY K 8644 were tested at $+5 \mathrm{mV}$, where the open time histograms were almost always fitted reasonably well by a single exponential provided that no depolarizing prepulses were given. Figure $11 a$ shows the control $\mathrm{Ca}^{2+}$ channel openings recorded at $+5 \mathrm{mV}$ in response to the depolarizing pulses from the holding voltage of $-60 \mathrm{mV}$. The open time histogram of the openings in the absence of BAY K 8644 is shown in Figure $12 a$ (histogram a). The histogram was fitted with a single-exponential component with a time constant of $0.60 \mathrm{msec}$. Figure $11 \mathrm{~b}$ shows the channel activity recorded after addition of $5 \mu \mathrm{M}$ BAY K 8644 to bath. This level is a saturating concentration of this drug (Brown et al., 1984a; Hess et al., 1984). Long openings were observed in addition to the short openings similar to those observed before the drug application. Both short and long openings were observed within 1 trace. The open time histogram was fitted by a sum of 2 exponential components, one with a time constant $1.0 \mathrm{msec}$ and the other with $18 \mathrm{msec}$ (Fig. 12, histogram b). BAY K 8644-produced long openings have a time constant of more than $12 \mathrm{msec}$, at least 2-3 times greater than 


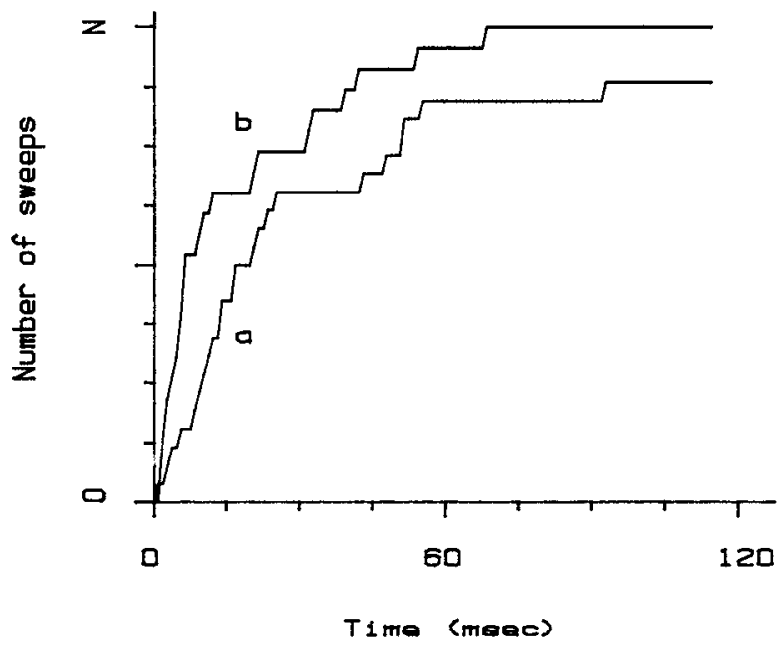

Figure 13. Comparison of the first latencies of the "short" and "long" openings of BAY K 8644-treated $\mathrm{Ca}^{2+}$ channels. Histogram $a$ shows the first latencies of the open events with durations $<4 \mathrm{msec} ; b$ shows the first latencies of the events with durations $\geq 4 \mathrm{msec}$. Open time histogram of the date used to generate the first latency histograms was fitted with a sum of 2 exponentials with time constants of 1.0 and 18 msec. Their relative amplitudes were 0.62 and 0.38 , respectively. The number of sweeps $(N)$ in the "short" group was 26 and of the events in the "long" group was 23 .

that of the long openings induced by large depolarization in the absence of BAY K 8644. In the presence of BAY K 8644, depolarizing prepulses did not affect time constants of the 2 open time components noticeably. However, the relative amplitude of the long component was greater than that observed without the prepulses.

The first latencies of the BAY K 8644-treated channels were analyzed further by separating the traces into 2 groups as before using the duration of the first opening in each depolarizing epoch as the criterion (Fig. 13). The traces were included in the "short" group if the first openings were shorter than the criterion (4 $\mathrm{msec}$ ) and otherwise they were included in the "long" group. In the patch shown in Figure 13, time constants of the 2 exponential components in the open time histogram were 1.0 and $18 \mathrm{msec}$ and their relative amplitudes were 0.62 and 0.38 . Thus, $96 \%$ of the events in the "long" group belonged to the long component of the open time histogram and 4\% in the "long" group belonged to the short component of the open time histogram. Similarly, $89 \%$ of the events in the "short" group belonged to the short component of the open time histogram and $11 \%$ of the "short" group to the long component of the open time histogram. The first latency for the "long" group was shorter than that for the "short" group. Simple average first latencies for the "short" and "long" were 45 and $20 \mathrm{msec}$ in Figure 13. The differences between the 2 histograms were significant at 0.1 but not 0.05 level using the Kolmogorov-Smirnov 2-sample procedure. The differences in the first latencies of the 2 groups were observed regardless of the sampling rate used to record the data.

Effects of BAY K 8644 on the open time were not consistently observed, however. Some of the channels tested did not respond to the drug application even though the pretreatment characteristics of these channels were identical to those of the channels that did respond to BAY K 8644.

\section{Discussion}

The results showed that 3 exponential components could exist in the open time histograms of $\mathrm{Ca}^{2+}$ channels under various conditions. At low voltages, short openings with a time constant of less than $1 \mathrm{msec}$ are most frequently observed. Greater depolarization induces the second type of openings with a time constant of 3-5 msec. This type of opening was responsible for the slowly decaying component of the tail current following large depolarizing prepulses. BAY K 8644 produces a very long third component with a time constant of more than $12 \mathrm{msec}$.

The long openings induced by depolarizations and BAY K 8644-produced long openings differ in the following properties: (1) Time constant of the depolarization-induced component was usually 3-5 msec, whereas that of BAY K 8644-produced component was greater than $12 \mathrm{msec}$. (2) In the absence of the drug, the first latencies of the "short" group openings were faster than those of the "long" group openings (Fig. 6). In the presence of BAY K 8644, the first latencies of the "short" openings were slower than those of the "long" group openings (Fig. 13).

\section{Multiple channel types or multiple open states?}

There are 2 obvious interpretations of the results presented. (1) Multiple types of $\mathrm{Ca}^{2+}$ channels exist. Different types of $\mathrm{Ca}^{2+}$ channels are responsible for the different components of the open time histograms. (2) Kinetically different open states of 1 type of $\mathrm{Ca}^{2+}$ channel are responsible for the different open time components. Previously, different types of $\mathrm{Ca}^{2+}$ channels in 1 cell typc have becn discovered mainly on the basis of the following observations (see Matteson and Armstrong, 1986): (1) Different unitary current amplitudes (Carbone and Lux, 1984b; Nilius et al., 1985; Nowycky et al., 1985a); (2) different activation, inactivation, or deactivation properties depending on the holding voltage of more negative than $0 \mathrm{mV}$ (Carbone and Lux, 1984a, b; Tsunoo et al., 1984; Armstrong and Matteson, 1985; Bean, 1985; Nilius et al., 1985; Nowycky et al., 1985a; Yoshii et al., 1985; Matteson and Armstrong, 1986); (3) different sensitivities to wash-out or patch excising (Carbone and Lux, 1984a, b; Armstrong and Matteson, 1985; Nilius et al., 1985; Tsunoo et al., 1985); (4) very different activation or deactivation properties with different charge carriers (Armstrong and Matteson, 1985; Bean, 1985; Matteson and Armstrong, 1986); and (5) different ion, agonist, or antagonist sensitivities (Fox and Krasne, 1984; Armstrong and Matteson, 1985; Nilius et al., 1985; Nowycky et al., 1985a; Tsunoo et al., 1985; Matteson and Armstrong, 1986). Several lines of evidence suggest that only 1 type of $\mathrm{Ca}^{2+}$ channel contributed significantly to the data obtained. $\mathrm{Ca}^{2+}$-channel openings found in this study were similar in amplitude regardless of the open durations. Neither the single $\mathrm{Ca}^{2+}$-channel activity nor the whole-cell $\mathrm{Ca}^{2+}$-channel currents were affected by weak depolarizing or hyperpolarizing prepulses (unpublished observations). After the patch excision, all the channel activity ceased within $60-120 \mathrm{sec}$ (Fenwick et al., 1982b; and unpublished observations). Time constants of the 2 open time components found in this study are similar to those of 2 types of $\mathrm{Ca}^{2+}$ channels found by Carbone and Lux (1984b). However, other properties of the $\mathrm{Ca}^{2+}$ channel found in this study are totally different from those found by Carbone and Lux (1984b). For example, 2 types of $\mathrm{Ca}^{2+}$ channels observed by Carbone and Lux differed in the unitary current amplitude by $30-40 \%$, whereas the 2 types of openings in this study are indistinguishable in the unitary current amplitude. Biex- 
ponential decay of the average current obtained in this study (see Fig. $7 b$ ) somewhat resembles the results obtained by Armstrong and Matteson (1985) and Matteson and Armstrong (1986). They observed 2 components in the whole-cell tail currents and attributed this to 2 types of $\mathrm{Ca}^{2+}$ channels that differed in the deactivation kinetics. The slowly decaying component of Armstrong and Matteson (1985) and of Matteson and Armstrong (1986) was inactivated by $100 \mathrm{msec}$ depolarizing prepulses, whereas the slowly decaying component seen in this study was present even after $1 \mathrm{sec}$ prepulses. Thus, if more than 1 type of $\mathrm{Ca}^{2+}$ channel were responsible for the multiple open time components observed, the differences must be much more subtle than those previously described for the $\mathrm{Ca}^{2+}$ channels in other preparations. The variability found in the relative amplitudes of the short and long components of the open time histogram may argue for multiple types of $\mathrm{Ca}^{2+}$ channels. However, it is worth mentioning that in the cell-attached configuration, intracellular factors are not experimentally controlled. Differences in such uncontrolled variables as intracellular free $\mathrm{Ca}^{2+}$ or other second messenger levels may influence the $\mathrm{Ca}^{2+}$ channel properties. In the absence of clear evidence for multiple types of $\mathrm{Ca}^{2+}$ channels that contributed significantly to the data obtained in this study, it is suggested that the multiple components in the open time histograms represent different open states of 1 type of $\mathrm{Ca}^{2+}$ channel in chromaffin cells.

\section{Comparison with previous studies}

Previous studies have found that the open time histogram of voltage-dependent $\mathrm{Ca}^{2+}$ channels could be well fitted by a single exponential, indicating that only 1 open state exists (Brown et al., 1982; Fenwick et al., 1982b; Cavalie et al., 1983). This observation led to the sequential 3-state model of $\mathrm{Ca}^{2+}$ channel activation. Recent studies of dihydropyridine effects on heart cells suggest that $\mathrm{Ca}^{2+}$ channels could exhibit 3 different types of gating behavior with different open time properties (Hess et al., 1984). BAY K 8644 produces the type of gating with a longlived open state. Even in the absence of BAY K 8644, long openings similar to that observed with the drug were found at very low frequencies (Hess et al., 1984; Nowycky et al., 1985a, b). Nowycky et al. (1985b) indicated that the occurrence of long openings in the absence of BAY K 8644 in sensory neurons was not determined by the membrane voltage.

The results of this study show that membrane depolarization does induce long openings in chromaffin cell $\mathrm{Ca}^{2+}$ channels. This effect of depolarization has not been documented in other preparations. This is in part because $\mathrm{Ca}^{2+}$ channels in other preparations studied so far appear to show significant voltagedependent inactivation and those in chromaffin cells do not. Long depolarizing prepulses would cause inactivation of the $\mathrm{Ca}^{2+}$ channels in other preparations and the tail openings would not be observed.

\section{Model of activation}

To explain the effects of various dihydropyridines on $\mathrm{Ca}^{2+}$ channel gating, Hess et al. (1984) used a concept of "modes" of gating. Each mode is modeled by a 3-state scheme with 1 open state and different dihydropyridines favor certain mode(s). This was proposed in part because the transitions between the modes were slow compared with the primary gating of the $\mathrm{Ca}^{2+}$ channels. Depolarization-induced long openings occur on a faster time scale as a part of the primary gating. Although it is possible to explain the data obtained using "modes," the more traditional state-model schemes appear more useful in a discussion of the results presented here.

Since 2 exponential components were present in the open time histograms, at least 2 open states are required to explain the activation of normal $\mathrm{Ca}^{2+}$ channels in chromaffin cells. Depolarization drives the channel to the second longer-lasting open state. Larger depolarizing prepulses drive the channel to the second longer open state, and long "tail" openings were observed immediately after the pulse. Simple linear sequential models with 2 open states are not readily consistent with the results because the first latencies of the "short" and "long" openings differed. The channel can go directly to the long-lived open state without entering the short open state. Branched models with 2 open states are consistent with the results. At least 3 closed states are necessary since 3 exponential components were found in the closed time histogram of the tail $\mathrm{Ca}^{2+}$ channel activity. Two of the closed states appeared to be involved in the transitions leading to the "short" openings, and the last closed state is involved in the transitions from the "long" open state back to the "short" open state, as shown by comparison of closed time histograms of the events with and without depolarizing prepulse. Transitions from the resting closed state to the long open state probably involve more closed states than those to the short open state because the first latencies of the "long" openings were slower than those of the "short" openings. In addition to the 3 closed states, possibly a fourth closed state exists. This closed state would account for the brief closures observed in some of the long openings (see Fig. $7 b$ ) and for the very short component of the closed time histogram of the events following "long" tail openings (Fig. 10). One of the relatively simple models that is consistent with the data obtained is

$$
\begin{array}{cc}
\mathrm{C}_{0}-\mathrm{C}_{1}-\mathrm{C}_{2}-\mathrm{C}_{3} \\
\mathrm{I} & \mid \\
\mathrm{O}_{\text {short }} & \mathrm{O}_{\text {long }}
\end{array}
$$

At rest, the channel is in $\mathrm{C}_{0}$. Depolarization drives the channel to $\mathrm{O}_{\text {short }}$. With greater depolarization, the channel enters $\mathrm{O}_{\text {long }}$ more frequently. In addition to these closed and open states, some inactivated states must exist since the plateau levels of the first latency histograms were not necessarily unity. It is not clear where the BAY K 8644-produced long-lived open state fits into this scheme. Because BAY K 8644-produced long openings differ from the short openings observed in the presence of the drug in the first latency property and because very long openings were observed in the absence of BAY K 8644, at least in some cells (Hess et al., 1984; Nowycky et al., 1985b), any schemes involving BAY K 8644 binding only to the "short" open state that is normally visited in the absence of the drug are not likely.

\section{Possible physiological significance}

The $\mathrm{Ca}^{2+}$ channel currents in chromaffin cells could be enhanced by prior depolarizing pulses (Fenwick et al., 1982b; Hoshi et al., 1984). This phenomenon has been termed as facilitation of $\mathrm{Ca}^{2+}$ channel currents. The long-lived open state favored by depolarization reported in this study could account, at least qualitatively, for facilitation of $\mathrm{Ca}^{2+}$ channel currents. A large depolarizing pulse would drive the channels to the long-lived open state $\left(\mathrm{O}_{\text {long }}\right)$. If the next pulse is applied before the channels 
had time to return to resting closed state $\left(C_{0}\right)$, the resulting current would be greater in amplitude because some of the channels would re-enter the long open state $\left(\mathrm{O}_{\text {long }}\right)$ instead of the short open state normally visited $\left(\mathrm{O}_{\text {shor }}\right)$. Gradually, the current amplitude would decline to the same level as that elicited without depolarizing prepulses. If similar behavior is present in intact chromaffin cells, chromaffin cells would then secrete greater amounts of catecholamines with each action potential, resulting in activity-dependent facilitation of secretion. Although facilitation of $\mathrm{Ca}^{2+}$ channels themselves has been ruled out as the mechanism of monosynaptic facilitation of transmitter release in some synapses (e.g., Charlton et al., 1982), it could be one of the mechanisms of facilitation in other synapses.

\section{References}

Armstrong, C. M., and D. R. Matteson (1985) Two distinct populations of calcium channels in a clonal line of pituitary cells. Science 227: 65-67.

Bean, B. P. (1985) Two kinds of calcium channels in canine atrial cells. J. Gen. Physiol. 86: 1-80.

Bevington, P. R. (1969) Data Reduction and Error Analysis for the Physical Sciences, McGraw-Hill, New York.

Brown, A. M., H. Camerer, D. L. Kunze, and H. D. Lux (1982) Similarity of unitary $\mathrm{Ca}^{2+}$ currents in three different species. Nature 299: 156-158.

Brown, A. M., D. L. Kunze, and A. Yatani (1984a) The agonist effect of dihydropyridines on $\mathrm{Ca}$ channels. Nature 311: 570-572.

Brown, A. M., D. L. Wilson, and H. D. Lux (1984b) Activation of calcium channels. Biophys. J. 45: 125-127.

Brown, A. M., H. D. Lux, and D. L. Wilson (1984c) Activation and inactivation of single calcium channels in snail neurons. J. Gen. Physiol. 83: 751-769.

Carbone, E., and H. D. Lux (1984a) A low voltage-activated calcium conductance in embryonic chick sensory neurons. Biophys. J. 46:413418.

Carbone, E., and H. D. Lux (1984b) A low voltage-activated, fully inactivating $\mathrm{Ca}$ channel in vertebrate sensory neurons. Nature 310 : 501-502.

Cavalie, A., R. Ochi, D. Pelzer, and W. Trautwein (1983) Elementary currents through $\mathrm{Ca}^{++}$channels in pig myocytes. Pfluegers Arch. 398: 284-297.

Chad, J. E., and R. Eckert (1984) Calcium domains associated with individual channels can account for anomalous voltage relations of Ca-dependent responses. Biophys. J. 45: 993-999.

Charlton, M. P., S. J. Smith, and R. S. Zucker (1982) Role of presynaptic calcium ions and channels in synaptic facilitation and depression at the squid giant synapse. J. Physiol. (Lond.) 323: 173-193.

Colquhoun, D., and F. J. Sigworth (1983) Fitting and statistical analysis of single channel records. In Single-Channel Recording, B. Sakmann and E. Neher, eds., pp. 191-263, Plenum, New York.
Fenwick, E. M., A. Marty, and E. Neher (1982a) A patch-clamp study of bovine chromaffin cells and of their sensitivity to acetylcholine. J. Physiol. (Lond.) 331: 577-597.

Fenwick, E. M., A. Marty, and E. Neher (1982b) Sodium and calcium channels in bovine chromaffin cells. J. Physiol. (Lond.) 331: 599635.

Fogelson, A., and R. S. Zucker (1985) Presynaptic calcium diffusion from various arrays of single channels: Implications for transmitter release and synaptic facilitation. Biophys. J. 48: 1003-1017.

Fox, A. P., and S. Krasne (1984) Two calcium currents in Neanthes arenaceodentatus egg cell membranes. J. Physiol. (Lond.) 356: 491505.

Hagiwara, S., and H. Ohmori (1983) Studies of single calcium channel currents in rat clonal pituitary cells. J. Physiol. (Lond.) 336:649661.

Hamill, O. P., A. Marty, E. Neher, B. Sakmann, and F. J. Sigworth (1981) Improved patch-clamp technique for high resolution current recording from cells and cell-free membrane patches. Pfluegers Arch. 391: 85-100.

Hess, P., J. B. Lansman, and R. W. Tsien (1984) Different modes of Ca channel gating behaviour favoured by dihydropyridine $\mathrm{Ca}$ agonists and antagonists. Nature 311: 538-544.

Hoshi, T., J. Rothlein, and S. J. Smith (1984) Facilitation of $\mathrm{Ca}^{2+}$ channel currents in bovine adrenal chromaffin cells. Proc. Natl. Acad. Sci. USA 81: 5871-5875.

Kokubun, S., and H. Reuter (1984) Dihydropyridine derivatives prolong the open state of $\mathrm{Ca}$ channels in cultured cardiac cells. Proc. Natl. Acad. Sci. USA 81: 4824-4827.

Matteson, D. R., and C. M. Armstrong (1986) Properties of two types of calcium channels in clonal pituitary cells. J. Gen. Physiol. 87: 161182.

Nilius, B., P. Hess, J. B. Lansman, and R. W. Tsien (1985) A novel type of calcium channel in ventricular heart cells. Nature 316: 443446.

Nowycky, M., A. P. Fox, and R. W. Tsien (1985a) Three types of neuronal calcium channel with different calcium agonist sensitivity. Nature 316: 440-443.

Nowycky, M., A. P. Fox, and R. W. Tsien (1985b) Long-opening mode of gating of neuronal calcium channels and its promotion by the dihydropyridine calcium agonist BAY K 8644. Proc. Natl. Acad. Sci. USA 82: 2178-2182.

Simon, S. M., and R. R. Llinás (1985) Compartmentalization of the submembrane calcium activity during calcium flux and its significance in transmitter release. Biophys. J. 48: 485-498.

Tsunoo, A., M. Yoshii, and T. Narahashi (1984) Two types of calcium channels in neuroblastoma cells and their sensitivities to cyclic AMP. Soc. Neurosci. Abstr. 10: 527.

Tsunoo, A., M. Yoshii, and T. Narahashi (1985) Differential block of two types of calcium channels in neuroblastoma cells. Biophys. J. 47: 433a.

Yoshii, M., A. Tsunoo, and T. Narahashi (1985) Different properties in two types of calcium channels in neuroblastoma cells. Biophys. J. 47: 433a. 